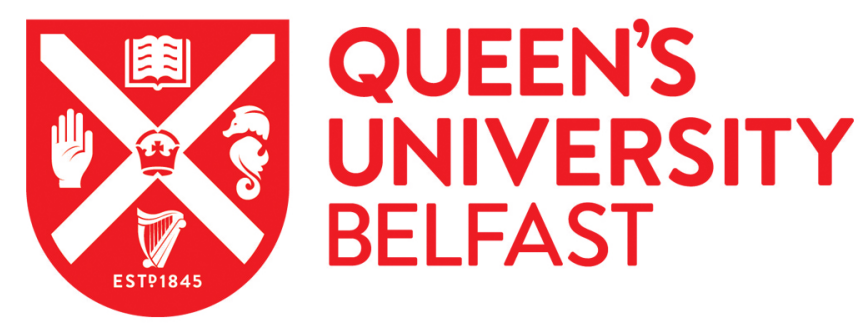

\title{
RNAi screen identifies Jarid1b as a major regulator of mouse HSC activity
}

Cellot, S., Hope, K. J., Chagraoui, J., Sauvageau, M., Deneault, É., MacRae, T., Mayotte, N., Wilhelm, B. T., Landry, J. R., Ting, S. B., Krosl, J., Humphries, K., Thompson, A., \& Sauvageau, G. (2013). RNAi screen identifies Jarid $1 \mathrm{~b}$ as a major regulator of mouse HSC activity. Blood, 122(9), 1545-1555. https://doi.org/10.1182/blood-2013-04-496281

\section{Published in:}

Blood

\section{Document Version:}

Peer reviewed version

Queen's University Belfast - Research Portal:

Link to publication record in Queen's University Belfast Research Portal

\section{General rights}

Copyright for the publications made accessible via the Queen's University Belfast Research Portal is retained by the author(s) and / or other copyright owners and it is a condition of accessing these publications that users recognise and abide by the legal requirements associated with these rights.

Take down policy

The Research Portal is Queen's institutional repository that provides access to Queen's research output. Every effort has been made to ensure that content in the Research Portal does not infringe any person's rights, or applicable UK laws. If you discover content in the Research Portal that you believe breaches copyright or violates any law, please contact openaccess@qub.ac.uk. 


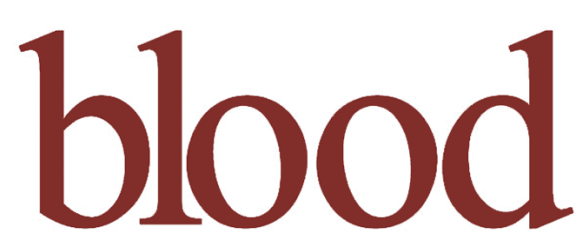

Prepublished online June 18, 2013;

doi:10.1182/blood-2013-04-496281

\section{RNAi screen identifies Jarid1b as a major regulator of mouse HSC activity}

Sonia Cellot, Kristin J. Hope, Jalila Chagraoui, Martin Sauvageau, Éric Deneault, Tara MacRae, Nadine Mayotte, Brian T. Wilhelm, Josette R. Landry, Stephen B. Ting, Jana Krosl, Keith Humphries, Alexander Thompson and Guy Sauvageau

Information about reproducing this article in parts or in its entirety may be found online at:

http://bloodjournal.hematologylibrary.org/site/misc/rights.xhtml\#repub_requests

Information about ordering reprints may be found online at:

http://bloodjournal.hematologylibrary.org/site/misc/rights.xhtml\#reprints

Information about subscriptions and ASH membership may be found online at:

http://bloodjournal.hematologylibrary.org/site/subscriptions/index.xhtml

Advance online articles have been peer reviewed and accepted for publication but have not yet appeared in the paper journal (edited, typeset versions may be posted when available prior to final publication). Advance online articles are citable and establish publication priority; they are indexed by PubMed from initial publication. Citations to Advance online articles must include the digital object identifier (DOls) and date of initial publication.

Blood (print ISSN 0006-4971, online ISSN 1528-0020), is published weekly by the American Society of Hematology, 2021 L St, NW, Suite 900, Washington DC 20036.

Copyright 2011 by The American Society of Hematology; all rights reserved.

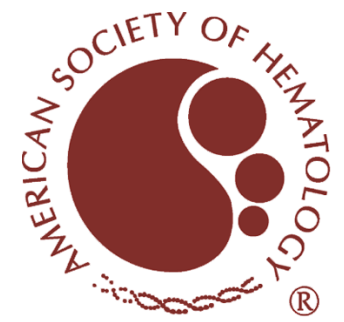




\section{RNAi screen identifies Jarid1b as a major regulator of mouse HSC activity}

Sonia Cellot ${ }^{1,2,3}$, Kristin J. Hope ${ }^{1}$, Jalila Chagraoui ${ }^{1}$, Martin Sauvageau ${ }^{1}$, Éric Deneault ${ }^{1}$, Tara MacRae $^{1}$, Nadine Mayotte ${ }^{1}$, Brian T. Wilhelm ${ }^{1,}$ Josette R. Landry $^{1}$, Stephen B. Ting ${ }^{1,8}$, Jana Krosl $^{1}$, Keith Humphries ${ }^{4}$, Alexander Thompson ${ }^{5}$ and Guy Sauvageau ${ }^{1,2,6,7 *}$

${ }^{1}$ Institute for Research in Immunology and Cancer (IRIC), Université de Montreal, Montreal, Quebec, Canada H2W 1R7; ${ }^{2}$ Faculty of Medicine, Université de Montreal, H3C 3J7; ${ }^{3}$ Division of Hematology, Ste-Justine Hospital, Montreal, H3T 1C5, ${ }^{4}$ Terry Fox Laboratory, British Columbia Cancer Agency, and Department of Medicine, University of British Columbia, Vancouver, BC, ${ }^{5}$ Centre for Cancer Research and Cell Biology, Queen's University Belfast, Northern Ireland, BT9 7BL ${ }^{6}$ Division of Hematology, MaisonneuveRosemont Hospital, Montreal, H1T 2M2; ${ }^{7}$ Leukemia Cell Bank of Quebec, MaisonneuveRosemont Hospital, Montreal, H1T 2M2; ${ }^{8}$ Monash University, Melbourne, Australia.

Running title: Jarid1b negatively influences self-renewal

*Correspondence:

Guy Sauvageau

Université de Montreal

C.P.6128, succursale Centre-Ville

Montreal, Quebec, Canada H3C 3J7

E-mail : guy.sauvageau@umontreal.ca 
Key Point: Jarid1b knockdown promotes enhanced HSC activity

\begin{abstract}
Histone methylation is a dynamic and reversible process proposed to directly impact on stem cell fate. The Jumonji (JmjC) domain-containing family of demethylases comprises 27 members which target mono-, di- and tri-methylated lysine residues of histone (or nonhistone) proteins. To evaluate their role in regulation of hematopoietic stem cell (HSC) behaviour we performed an in vivo RNAi-based functional screen and demonstrated that Jarid1b and Jhdm1f play opposing roles in regulation of HSC activity. Decrease in Jaridlb levels correlated with an in vitro expansion of HSCs with preserved long term in vivo lympho-myeloid differentiation potential. Through RNA sequencing analysis Jaridlb knockdown was associated with increased expression levels of several HSC regulators (Hoxa7, Hoxa9, Hoxa10, Hes1, Gata2) and reduced levels of differentiation associated genes. shRNA against Jhdmlf, in contrast, impaired hematopoietic reconstitution of bone marrow cells. Together, our studies identified Jarid1b as a negative, and Jhdmlf as a positive regulator of HSC activity.
\end{abstract}




\section{INTRODUCTION}

Multipotent hematopoietic stem cells (HSCs) ensure sustained production of lineage committed blood cells throughout life. The pool of long-lived HSCs is preserved due to their inherent capacity to undergo self-renewal divisions. Cell fate decisions result from integrated influences of various nuclear factors, including chromatin modifiers that regulate access of transcriptional machinery to specified genomic loci. Chromatin, consisting of intertwined DNA, histone and non-histone proteins, can be covalently modified by epigenetic effectors. DNA methyltransferases (DNMTs) modify carbon-5 of cytosine bases within cytosineguanosine dinucleotides $(\mathrm{CpG})$ frequently located proximal to or in promoters ${ }^{1}$. In mammalian cells, the mechanism and effectors of DNA demethylation are less well understood, but recent reports suggest this process likely requires the activity of the TET enzyme family ${ }^{2,3}$. Post-translational modifications of histones include methylation, acetylation, phosphorylation, ubiquitination, sumoylation or ADP-ribosylation (reviewed in ${ }^{4}$ ) and introduce changes in local chromatin topography that subsequently alter gene expression patterns in developmental stage and cell context-specific manners.

Methylation of histone residues represents a classical paradigm linking epigenetics to cell fate and identity, best illustrated by the antagonistic forces of Polycomb (PcG) and Trithorax (Trx) group protein complexes on regulation of key developmental loci such as Hox gene clusters (reviewed $\mathrm{in}^{5}$ ). In general, PcG protein repressor complexes PRC2 and PRC1 are associated with gene silencing, and Trx complexes (compass-like or MLL, Mixed Lineage Leukemia, complexes) with gene activation. The histone methyltransferase (HMT) Enhancer of Zeste Homolog 2 (EZH2) of the PRC2 complex catalyzes tri-methylation of lysine 27 on histone $\mathrm{H} 3$ (H3K27me3). This covalent mark serves as a docking site for the PRC1 complex which mono-ubiquitinates lysine 119 of histone H2A (H2AK119Ub) resulting in gene silencing. MLL complexes counteract these epigenetic marks via tri-methylation of lysine 4 
on histone $\mathrm{H} 3$ (H3K4me3) at transcription start sites, a mark associated with active gene transcription $^{6}$ and recruitment of H3K27me3 demethylases UTX and JMJD3 ${ }^{7-9}$. Additional Trx-mediated modifications such as acetylation of H3K27 (H3K27Ac) and di-methylation of H3K36 (H3K36me2) further oppose the PcG mediated gene repression.

Histone methylation status on lysine $(\mathrm{K})$ or arginine $(\mathrm{R})$ residues is reported to evolve through highly dynamic and finely regulated processes (reviewed in ${ }^{10}$ ). Histone demethylases (HDMs) integrate into multi-unit complexes resulting in removal of methylation marks by amine oxidation, deimination ${ }^{11}$ or hydroxylation. The lysine specific demethylase 1 (LSD1/KDM1A)-related HDM can demethylate mono- and di-methylated lysine residues. Jumonji C $(\mathrm{JmjC})$ domain-containing HDMs $(\mathrm{n}=27)$ are capable of removing all three lysine methylation states by an oxidative reaction requiring $\alpha$-ketoglutarate and iron $\left(\mathrm{Fe}^{2+}\right)$ as cofactors. Like the LSD1 family, JmjC/JARID1 proteins act as components of multi-subunit complexes, with non-catalytic domains proposed to mediate protein-protein interactions involved in regulation of demethylase activity and/or target specificity (reviewed in ${ }^{12}$ ). In addition, JMJD6 demethylates arginine residues ${ }^{13}$, and bacterial Jumonji domain-containing AlkB protein is involved in DNA demethylation and repair ${ }^{14,15}$ suggesting that JmjC substrates include non-histone targets.

JmjC protein activity results in dynamic chromatin landscape changes which enable expression of distinct gene subsets required for self-renewal ${ }^{16}$, proliferation ${ }^{17}$, differentiation ${ }^{18-20}$, cellular senescence ${ }^{21}$ and cancer development ${ }^{22-24}$. In light of these findings, an established in vivo RNAi based screening strategy ${ }^{25}$ was undertaken, in a targeted way, to assess the impact of JmjC gene down-regulation on adult primary HSC cell fate. We identify Jarid1b as a negative regulator of HSC self-renewal and progenitor cell activity, while Jhdm1f positively influences blood reconstitution. Results from these experiments and possible downstream functional networks involved are presented. 


\section{METHODS}

\section{Construction of shRNA retroviral vectors}

For each gene target, 3-5 shRNAs were designed as single stranded oligonucleotides also incorporating miR-30 flanking arms using the RNAi Central shRNA design tool at http://cancan.cshl.edu/RNAi central/main2.cgi and our previously established methodology $y^{25}$

\section{Mice}

C57BL/6J $\left(\mathrm{CD} 45.2^{+}\right)$transplant recipients and C57BL/6Ly-Pep3b $\left(\mathrm{CD} 45.1^{+}\right)$congenic bone marrow donor mice were bred and manipulated in a specific pathogen-free animal facility. Experimental procedures were revised and approved by the University of Montreal animal ethics committee (Comité de Déontologie de l'Expérimentation sur les Animaux de l’Université de Montréal).

\section{Flow cytometry}

Negative selection of hematopoietic lineage marker $\left(\mathrm{GR}-1^{+}, \mathrm{B} 220^{+}\right.$, Ter119 $\left.{ }^{+}\right)$expressing cells $\left(\operatorname{Lin}^{-}\right)$was performed as described ${ }^{25}$. Lin ${ }^{-}$bone marrow fraction was subsequently stained with PE-Cy7-conjugated anti-cKit, PE-Cy5-conjugated anti-Sca1 (eBioscience), PEconjugated anti-CD150 (BioLegend) and FITC-conjugated anti-CD48 (BD Biosciences) antibodies, followed by isolation of HSC-enriched $\mathrm{PE}-\mathrm{Cy} 5-\mathrm{Sca} 1^{+} / \mathrm{PE}-\mathrm{Cy} 7-\mathrm{cKit}^{+} / \mathrm{PE}-$ $\mathrm{CD} 150^{+} / \mathrm{FITC}^{-C D} 48^{-} / \mathrm{APC}^{-L_{i n}}{ }^{-}$cell population. Day E14.5d.p.c. fetal liver derived HSCs were purified from the Lin $^{-}$cell populations by isolating the fraction of $\mathrm{PE}-\mathrm{Cy} 5-\mathrm{Sca} 1^{+} / \mathrm{PE}-$

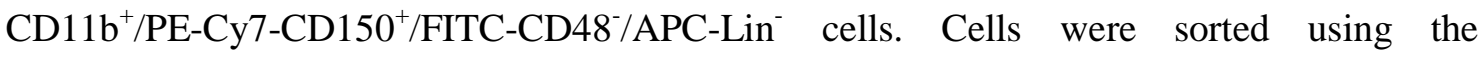
FACSAria cell sorter (Becton-Dickinson, San Jose, CA, USA. The frequency of LT-HSC in the sorted populations (Table $\mathrm{S} 1)$, the proportions of transduced $\left(\mathrm{GFP}^{+}\right)$transplant-derived 
$\left(\mathrm{CD} 45.1^{+}\right)$peripheral blood leukocytes ${ }^{26}$ and contribution of these cells to reconstitution of hematopoietic lineages ${ }^{25,26}$ were determined as described.

\section{HSC/progenitor cell culture, retroviral infection and transplantation}

Suspension cell cultures of $\mathrm{HSC} /$ progenitor cell enriched populations, generation of retrovirus-producing GP+E-86 cells and infection of the sorted HSC/progenitor cells were performed as described ${ }^{26}$. For validation assays, $1500 \mathrm{CD}^{2} 50^{+} \mathrm{CD} 48^{-} \mathrm{Lin}^{-}$bone marrow derived cells were introduced in co-culture with retroviral producers in 96-well plates ${ }^{26}$. After 5-day incubation (day 0), the total cell content of each well was harvested, and partitioned for transplantation and cell culture as previously reported ${ }^{25}$. Briefly, $1 / 8$ of cell suspension was transplanted into sublethally irradiated congenic recipients ( $n=2$ for each shRNA species). The remaining cells were cultured for additional 7 days and proportions corresponding to $1 / 8$ of the cell input transplanted in 3 recipient mice (day 7). To compensate for the shJhdmlfassociated loss of reconstituting activity, $1 / 4$ of day 0 cell suspensions was transplanted in each of the 3 recipients, and no continuing suspension cultures were initiated.

\section{Clonogenic progenitor cell assays}

The total numbers and distributions of myeloid clonogenic progenitors in various cell populations recovered from the 5-day co-culture with retroviral producers (day 0), or from the subsequent suspension cultures (day 5-7) were determined as described ${ }^{25}$.

\section{Microphotograpy}

Images of Wright-stained cytospin cell preparations were acquired using a Leica DMIRB microscope with an HCXPL FluotarL 40×/0.6 numeric aperture objective (Leica) and a Retiga EX-i camera (Q-Imaging). Images were transformed directly into TIFF files using 
Adobe Photoshop Version 6.0 (Adobe Systems). In situ images of colonies in semisolid media were acquired using the same set up, but using the HC Pl Fluotar 10X/0.30, Ph 1 lens.

\section{Competitive repopulating unit (CRU) assay}

These assays were performed as previously described ${ }^{25,26}$.

\section{Q-RT-PCR assessment of JmjC gene expression in HSC enriched populations}

Gene expression was assessed by Q-RT-PCR using the Roche LightCycler $^{\circledR} 480$ System (Roche, Basel, Switzerland). Reactions were performed in 384-well plates for 50 amplification cycles $\left(95^{\circ} \mathrm{C} 10 \mathrm{~s} ; 60^{\circ} \mathrm{C} 10 \mathrm{~s} ; 72^{\circ} \mathrm{C} 10 \mathrm{~s}\right)$. Reference Taqman ${ }^{\circledR}$ gene assay (Hprt) was purchased from Applied Biosystems. Primer sequences in Table S2, Delta Ct values in Table S3.

\section{ChIP-chip analysis}

Two-colour hybridizations on NimbleGen MM8 Deluxe Promoter HX1 arrays were carried

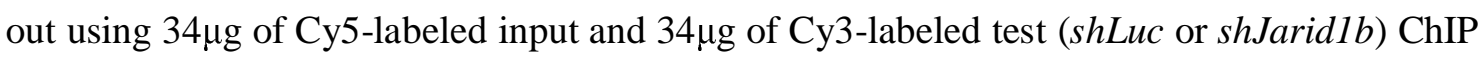
DNA using the NimbleGen hybridization kit as recommended by the manufacturer. Arrays were scanned at $5 \mu \mathrm{m}$ resolution using a GenePix4000B scanner (Molecular Devices). Data extraction and peak finding analysis was done using NimbleScan 2.5 and visualized in the UCSC genome browser.

\section{RNA sequencing analysis}

RNA sequencing was performed as previously described ${ }^{27}$. RNA was extracted from $1 \times 10^{6}$ cells for each test (sh3Jaridlb-GFP) and control (shLuc-GFP) culture condition. Cultures were initiated with $24,000 \mathrm{CD} 150^{+} \mathrm{CD} 48^{-} \mathrm{Lin}^{-}$bone marrow cells and expanded for 4 days 
following infection with the respective constructs. Cells from 2 independent cultures were isolated for each condition, and only cell populations with $>90 \%$ gene transfer were selected.

\section{shRNA-mediated knockdown in NUP98-Hoxa10AHD-transduced HSCs}

1500 purified $\mathrm{CD} 150^{+} \mathrm{CD}_{48} \mathrm{Lin}^{-}$bone marrow cells were co-cultured with irradiated (40 Gy) GP+E86 cells producing MSCV-NUP98-HOXA10HD-IRES-Puromycin (NA10HD) virus. After 4-day co-culture, cells were collected and cultured for 6 days in the presence of 10 $\mu \mathrm{g} / \mathrm{mL}$ of Puromycin, harvested and stained with APC/Cy7-conjugated anti-CD43 (BioLegend), APC-conjugated anti-Sca1, PE/Cy7-conjugated anti-Gr1 and PE/Cy5conjugated anti-F4/80 (eBioscience). The sorted NA10-transduced Sca $1^{+} \mathrm{CD} 43^{+} \mathrm{Gr} 1^{-} \mathrm{F} 4 / 80^{-}$ cell subpopulation was co-cultured with GP+E86 cells producing shLuc, sh3Jaridlb or shlMoz recombinant retroviruses. After 4 days, the nonadherent cells were recovered and expanded for additional 6 days. To assess the extent of differentiation in these cultures, cells were stained with PE/Cy7-conjugated anti-Gr1 and PE/Cy5-conjugated anti F4/80-PE/Cy5 antibodies. Data were acquired using BD LSRII cytometer and FACSDiva Version 4.1 software (BD Biosciences PharMingen), and analyzed using the FlowJo Version 7.6.4 software (TreeStar).

\section{Statistical Analysis}

Statistical analysis was conducted using Prism (Graphpad Software version 5) or SPSS. The two-tailed Student-t-test was performed throughout unless otherwise stated. Statistical significance was calculated at a $95 \%$ confidence level. 


\section{RESULTS}

\section{JmjC gene expression in HSC-enriched populations}

Expression profiles were obtained for all JmjC genes in sorted mouse bone marrow and fetal liver cell populations comprising $\geq 30 \%$ of functionally defined long-term-repopulating LTRHSCs, as evaluated by competitive repopulation unit (CRU) assays ${ }^{28}$ (Table S1). Results showed that all JmjC gene transcripts, except Hairless, were detected at relatively high levels (Fig. 1A). The histone acetyl-transferase MOZ (MYST3), reported as essential for HSC expansion $^{29,30}$ was also highly expressed in this fraction and chosen as a control for the functional screen. Transcript levels of four JmjC genes, namely Jarid1b, Jmjd2d, Fbxl10 and Jmjdlc, were notably increased in the LTR-HSC-enriched fractions relative to total bone marrow cells (Fig. 1B). In contrast, Jhdmld, Hspbapl and Hairless transcript levels were notably higher in more mature cells. Genes expressed higher in the LTR-HSC enriched population e.g. Jarid1b, Jmjd2d, Fbxl10 and Jmjdlc were assigned a HSC expression score of one, while genes that were higher expressed in mature cells were attributed negative scores (Fig. 1B, lower panel). Increased expression in LTR-HSCs implied a HSC biological role, and these candidates were prioritized in the functional studies.

\section{Functional in vivo RNAi-based primary screen}

The shRNA based screen tested 23 of the 27 known JmjC mouse genes (Fig. 1C) for their potential functional role in HSC biology. shRNA Luciferase (shLuc) was used as a negative control, while shRNA Moz (shMoz) and Nup98Hoxal0-homeodomain (NA10hd) overexpression were used as controls for the loss and gain of HSC activity, respectively (data not shown for NA10hd, and $\left.{ }^{31,32}\right)$. HDM-directed shRNA sequences $(\mathrm{n}=112$, Table S5) were subcloned into a LMP retroviral vector and assessed for their ability to modulate HSC/progenitor activity in vivo as previously reported ${ }^{25}$ (summarized in Fig. 1D). The 
biological impact of each shRNA was evaluated by serial sampling of peripheral blood from transplanted mice at early (3-4 weeks) and late (16-20 weeks) time points.

To prioritize candidates for validation and downstream functional studies, a "selection threshold scoring system (STS)," weighted for HSC-enriched genes, was established (Fig. 2A and Table S3). HSC activity was determined by the long-term blood engraftment potential of the transduced donor cells $\left(\mathrm{CD} 45.1^{+} \mathrm{GFP}^{+}\right.$cells) based on their contribution to blood leucocytes, calculated as a proportion of the total donor $\left(\mathrm{CD} 45.1^{+}\right)$population, which comprises both transduced and non-transduced cells (\%blood GFP $=\mathrm{CD} 45.1^{+} \mathrm{GFP}^{+}$cells/total CD45. $1^{+}$cells). The percentage of blood reconstitution of the transduced cells was then compared to the respective gene transfer (GT) level on the day of transplantation (day0), and this ratio (Fig.2B, y-axis) used to document an increased (ratio $>0.8072$ ) or decreased (ratio<0.2751) contribution to the donor graft (HSC activity score). This ratio was used as GT levels for the hairpins presented in Fig.2B ranged from 20-80\%, with an overall average of $49 \%$ as previously reported ${ }^{25}$ (see also Table S4 for complete data), and thus transduced cell expansion or attrition could be measured. Overall, six hits were identified: Jmjd2a, Jhdmlf and Jmjdlb (STS of 2); Jaridla, Jaridlb and Hiflan (STS of 3). Four of these genes; namely Jaridla, Jarid1b, Jmjd2a, Hiflan, were identified as potential negative regulators of HSC activity (Fig. 2B, green shaded areas), while Jhdmlf and Jmjdlb (Fig. 2B, red area), as putative positive regulators.

\section{JmjC HDM knockdown validation experiments}

Hit validation was further restricted to proven JmjC domain containing histone demethylases (HIF1AN demethylase excluded as it targets HIF1 $\alpha$ ) and for technical considerations validation of potential positive regulators was limited to Jhdmlf. The increased hematopoietic reconstitution levels observed with shRNA mediated knockdown of the three remaining hits; 
namely Jaridla, Jaridlb, Jmjd2a (Fig.2B) prompted us to examine how the transduced HSCs would behave in vitro, where control HSCs normally exhaust rapidly ${ }^{26}$. Validation experiments were performed (Fig. 3A) and a gain-of-function phenotype for Jaridla or $J m j d 2 a$ could not be confirmed upon shRNA transduction and prolonged in vitro culture (data not shown). Conversely, reducing Jaridlb levels in HSC populations by multiple shRNA moieties (shJaridlb 2, 3 and 4) clearly conferred an in vivo competitive advantage to freshly transduced cells compared to shLuc controls (Fig. 3B, left panel: $\mathrm{n}=3$ different shRNAs to Jaridlb, day 0 transplanted cells). As higher GT rates were achieved in the validation experiments (>80\%), blood reconstitution levels were measured as $\mathrm{CD}_{45.1}{ }^{+} \mathrm{GFP}^{+}$ cell percentages. The positive impact of shJaridlb on HSC activity was even more noticeable for cells transplanted after one week of in vitro culture (Fig. 3B, middle and right panels, cells transplanted after 7-day culture) to better detect HSC gain-of-function activity, as our previous studies demonstrated ${ }^{26}$. Proportions of shJaridlb-transduced cells $\left(\mathrm{GFP}^{+}\right)$in peripheral blood remained well above those determined for shLuc controls for up to 10 months (Fig. 3B). Knockdown of shJaridlb was determined for freshly transduced cells, and a $>40 \%$ decrease in expression observed for shJaridlb 2, 3 and 4 (Fig. 3C). Decreased HSC activity relative to control cells was confirmed with multiple shRNA constructs against $\operatorname{Jhdmlf}(\mathrm{n}=5)$, Fig. 3D,E. All five shRNAs against Jhdmlf had knockdown efficiencies $>40 \%$ (Fig. 3F). Validation experiments thus uncovered one negative (Jaridlb) and one positive (Jhdmlf) regulator of HSC activity. Further in vitro studies of shJhdmlf-transduced cells detected no significant change in proliferation or clonogenic progenitor activity of nucleated cells (Figure S1) indicating a distinct role for Jhdmlf in HSC repopulation ability. The striking impact of Jaridlb knockdown on blood reconstitution oriented research towards Jarid1b function. 


\section{Jarid1b knockdown decreases hematopoietic cell differentiation in vitro}

Sh2- or sh3Jaridlb-transduced primitive hematopoietic cell populations had a $\sim 1.5$-2-fold proliferative advantage in vitro compared to shLuc controls, while Moz knockdown decreased expansion of the transduced cells (Fig. 4A, left panel). The expanded shJaridlb-transduced populations comprised high proportions of morphologically immature cells (Fig. 4A, right panel), and lower percentages of differentiated $\left(\mathrm{Gr}^{+}\right)$myeloid cells than shLuc controls (Fig. 4B). Moreover, fractions of primitive ( $\left.\mathrm{Gr}^{-}\right)$shJaridlb-transduced cells were comparable to that determined in response to NA10hd, a well characterized enhancer of in vitro HSC/progenitor cell expansion, while a marked elevation in differentiation was observed for shMoz loss-of-function control (Fig. 4B). During the 7-day culture period, the numbers of shJaridlb-transduced clonogenic progenitor cells (colony forming cell, CFC) increased $~ 3-$ fold compared to shLuc and shMoz controls (Fig.4C). Jaridlb knockdown enhanced the proliferative capacity of individual CFCs compared to shMoz controls (Fig.4D), and promoted expansion of the highly proliferative granulocyte-macrophage progenitors (Fig. 4E). Although the total CFC contents of shLuc and shMoz control cultures were comparable (Fig. 4C), and both cell populations differentiated into granulocytes and macrophages (Fig. 4E), the antiproliferative effect of Moz knockdown was evident from the decrease in sizes of shMoz clones compared to shLuc controls (data not shown).

Q-RT-PCR assays involving selected candidates revealed a marked downregulation of differentiation associated genes Hairless $(\mathrm{Hr})$ and Pu.1 in shJaridlb-cells compared to shMoz control (Fig. 4F). No major changes in expression levels of genes regulating senescence $(C d k n 2 a(p 16)$ and $C d k n 2 d(p 19))$ or apoptosis $(B c l 2, M c l 1)$ were detected in shJaridlb-cells, while modest increases in $c-M y c$ and decreases in Madl levels resembled those determined for Hoxb4-overexpressing cells (data not shown, and ${ }^{33}$ ). Moz knockdown was, however, clearly associated with upregulation of $H r, C d k n 2 a$ and $C d k n 2 d$ expression. This suggests 
that Jaridlb knockdown promotes in vitro HSC/progenitor expansion by suppressing differentiation, while cells remained permissive to cell cycle re-entry. In contrast, reduced Moz expression enforced commitment to differentiation and senescence cell fate pathways.

\section{Jarid1b negatively regulates HSC self-renewal}

Transplant recipients of shJaridlb-cells had normal numbers of total bone marrow mononuclear cells (MNC), and no splenomegaly was observed (Fig. 5A, $1^{\text {st }}$ and $2^{\text {nd }}$ panels). Contributions of the transduced $\left(\mathrm{GFP}^{+}\right)$shLuc-and shJaridlb-cells to myeloid progenitor cell compartments were comparable (Fig. 5A, $3^{\text {rd }}$ panel), but an $\sim 8-10$-fold increase in the frequencies of shJaridlb-multilineage progenitors (Colony Forming Unit-Granulocyte, Erythroid, Macrophage, Megakaryocyte, CFU-GEMM) compared to controls was observed (Fig. 5A, $4^{\text {th }}$ panel). This difference in immature progenitor cell content remained benign, and no hematological abnormalities could be detected during the 12 month observation period. Moreover, transplanted shJaridlb-cells generated normal proportions of myeloid $\left(\mathrm{Mac}^{+} / \mathrm{CD} 11 \mathrm{~b}^{+}\right)$, B-lymphoid $\left(\mathrm{B} 220^{+} / \mathrm{CD} 45 \mathrm{R}^{+}\right)$and $\mathrm{T}$-lymphoid $\left(\mathrm{CD} 4^{+}, \mathrm{CD}^{+}\right)$progeny (Fig. 5B), suggesting that differentiation ability in vivo was not affected.

To examine if Jaridlb knockdown favoured self-renewal divisions, leading to expansion of HSC populations, equal numbers of $\mathrm{HSC}$-enriched $\left(\mathrm{CD} 150^{+} \mathrm{CD}^{4} 8^{-} \mathrm{Lin}^{-}\right)$cell populations were co-cultured with $s h L u c$ or shJaridlb retroviral producers. HSC frequencies were determined in samples immediately after cell sorting and after a cumulative 12-day ex vivo culture period (Fig. 5C, top panel), using the CRU assay. CRU numbers in cell populations recovered from shLuc cultures (Fig. 5C, green bar) were comparable to those determined for the input cell population (Fig. 5C, red bar) suggesting no major loss or gain of HSCs during the in vitro incubation. In contrast, the CRU numbers in shJaridlb cultures increased 8- to 20-fold above shLuc control samples, or sorted cells prior to shJaridlb infection (Fig. 5C, blue bars), 
suggesting that Jarid1b knockdown promoted the in vitro maintenance/expansion of long term-repopulating HSCs. Southern blot analyses of shJaridlb revealed a common proviral integration pattern between bone marrow (mostly myeloid, erythroid and B-), thymus (mostly T-) and spleen (B- and T-) cells of individual recipients (Fig. 5D) demonstrating multipotency and oligoclonal hematopoietic reconstitution of the expanded HSCs.

\section{Impact of Jarid1b knockdown on gene expression}

To examine downstream effects of Jaridlb knockdown, results of transcriptome next generation sequencing (RNAseq), Q-RT-PCR and ChIP-Chip assays were analyzed and compared to controls. The similarity in HSC expansion observed between Jaridlb knockdown and Hox gene overexpression ${ }^{31,33}$ and the recent report that JmjC members KDM6A (UTX) and KDM6B (JMJD3) are positive regulators of Hox gene expression ${ }^{21}$ prompted initial focus on the Hox family of transcription factors (Fig. 6A). Both RNAseq and Q-RT-PCR assays revealed that Jarid1b knockdown induced a 2 to 5-fold increase in 5' Hoxa gene (Hoxa5 to Hoxa11) expression levels compared to controls (Fig. 6A and Figure S2). RNAseq analysis identified upregulation of genes associated with key pathways such as erythroid differentiation, notch signalling and stem/progenitor cell function (Fig.6B and Figure S3), and downregulation of others involved in immune responses and differentiation (Fig. 6C and Figure S4). Several of the candidate downstream genes, including Hoxa7, Hes 1, HoxalO and Hoxb2, were identified as potential direct epigenetic targets by enrichment of the associated H3K4me3 mark in 5' loci as determined by ChIP-Chip assays (Fig. 6D and Figure S5). Supporting this possibility, non-regulated genes e.g. Hoxa2 demonstrated no proximal promoter H3K4me3 enrichment following Jarid1b knockdown (Figure S5). Jaridlb knockdown also correlated with downregulation of the previously reported putative JARID1 target Cav1 $^{34}$ (Table S7). 


\section{Study of epistasis between Jarid1b and Nup98Hoxa10-homeodomain}

To directly examine potential gene interaction of Jaridlb and Hoxa overexpression, HSC/progenitor cell populations were first transduced with NUP98Hoxa10-homeodomain (NA10hd) and the HSC-enriched populations (Sca1 ${ }^{+} \mathrm{CD}_{4} 3^{+} \mathrm{Gr1}^{-} \mathrm{F} 4 / 80^{-}$; Keith Humphries, personal communication) subsequently transduced with shJaridlb, shMoz, or control shLuc. The proportions of mature $\mathrm{GR} 1^{+} \mathrm{F} 4 / 80^{+}$cell fractions in each condition were evaluated as a measure of differentiation (Fig. 6E, upper panel). Results demonstrate that the combined effects of NA1Ohd overexpression and Jaridlb knockdown were additive, resulting in significant suppression of in vitro differentiation $(\mathrm{p}<0.0001$; Student $\mathrm{t}$-test) below the levels determined for control NA1Ohd+shLuc-cells (Fig. 6E, lower panel). In contrast, shMoz targeted knockdown overrode the maturation arrest imposed by NA1Ohd overexpression, and enforced differentiation above the levels determined for controls (Fig. 6E, lower panel).

Together, the data presented support a role for Jarid1b in regulating key loci implicated in HSC cell fate and identify Jarid1b as a negative regulator of in vitro HSC expansion.

\section{DISCUSSION}

Following the established pipeline strategy from HSC isolation and infection to in vivo functional assessment of hematopoietic reconstitution, the presented RNAi screen highlighted Jaridlb as a negative and Jhmdlf as a positive modulator of HSC activity. Due to defined inclusion criteria other HDMs should not be excluded as potential HSC modifiers. Akin to Hox gene overexpression, differentiation was restrained in shJaridlb-transduced HSC cultures as evidenced by more primitive cell morphology, reduced granulocytic maturation, and greater expansion of clonogenic progenitors relative to controls. After transplantation, ex vivo expanded HSCs were able to resume normal lympho-myeloid differentiation in recipient 
mice, in the absence of lineage skewing or hematological abnormalities, for up to one year. Logarithmic ex vivo expansion of shJaridlb-transduced HSCs was demonstrated by CRU assays indicating that Jarid1b modulation influences stem cell fate decisions. Oligoclonal origin of the repopulating HSC pool and inherent multipotency of shJaridlb-transduced parental stem cells was shown by proviral insertion patterns in long-term recipient mice. Mechanistically, the competitive advantage conferred to shJaridlb-transduced HSCs could be attributed in part to the selective up-regulation of 5' Hoxa genes. Segmental transcription of this chromosomal region is well documented ${ }^{35}$ and particularly targeted by epigenetic regulators such as MLL or its derived fusion oncoproteins both in normal and leukemic stem cells ${ }^{36}$. Interestingly, the $5^{\prime}$ Hoxa cluster is also targeted by the fusion oncoprotein NUP98JARID1A in a mouse model of myeloid leukemia ${ }^{37}$.

In agreement with the proposed substrate specificity of JARID1B for H3K4me $3^{34}$, we noted enrichment for this epigenetic mark on 5' Hoxa genes indicating that Jarid1b contributes to the negative regulation of Hoxa gene expression which when relieved following knockdown, leads in part to increased HSC activity. Enhancement of NA10hd-induced maturation arrest in the presence of reduced Jaridlb levels argues for regulation of additional cell fate determinants to account for the HSC phenotype seen. Comprehensive transcriptome analysis by RNAseq identified additional downstream genes, some of which are associated with key hematopoietic or stem cell associated pathways. Recent reports further support a role for Jarid1b in transcriptional regulation of cell fate associated genes. PU.1 induction of transcription factor EGR2 was reported to recruit Jarid1b to the miR-17-92 promoter site, resulting in $\mathrm{H} 3 \mathrm{H} 4$ demethylation and transcriptional silencing of the cluster required for monocyte maturation in a mouse model ${ }^{19}$. Schmitz et al., recently reported that Jaridlb depletion prevents neuronal differentiation of ESCs by indirectly preventing H3K4 
demethylation and silencing of pluripotency and germ cell-associated gene loci ${ }^{20}$. Similarly, H3K4me2/1 monoamine oxidase LSD1 was also deemed essential for proper hematopoietic progenitor differentiation $^{38}$.

We demonstrate that transcript levels of Jaridlb are increased in HSCs suggesting either a role in preventing unrestricted self-renewal divisions or in enabling downregulation of cell fate associated genes upon lineage commitment. Interestingly, 1q32 anomalies, which include Jarid1b, are common genetic mutations found in cells of chronic myeloid leukemia (CML) patients during disease progression characterized by a block in myeloid differentiation 39,40 . This observation supports the hypothesis that low Jarid1b levels maintain stem cell fate, which combined with BCR-ABL induced proliferation, could result in development of overt leukemia. In our studies, transplant recipients of shJaridlb-transduced cells never developed leukemia. However, all Jaridlb hairpins tested achieved similar gene knockdown $(\leq 50 \%)$, and more drastic outcomes following complete Jaridlb depletion cannot be ruled out. Two $J a r i d 1 b$ null alleles, one (exon 1 deletion) embryonic lethal ${ }^{41}$ the other (exon 6 deletion) no gross abnormalities, ${ }^{20}$ have recently been described. Precise elucidation of the role Jaridlb gene dosage plays in HSCs and leukemia development will thus likely require analyses of HSC-specific Jaridlb deletion.

Overall, the data presented supports a cellular and developmental stage specific effect of Jarid1b levels in modulation of HSC cell fate. To sustain stem cell fate, integrated influences from various epigenetic effectors promote an active state of transcription at multipotency loci (Fig.7 upper panel). Activity of chromatin modifiers, including JARID1B, should culminate in maintenance of the $\mathrm{H} 3 \mathrm{~K} 4 \mathrm{me} 3$ epigenetic mark on these loci, and exclusion of repressive marks, such as H3K9me3 or H3K27me3. Jhdm1f/PHF8 has recently been identified as a key regulator of ATRA response in acute promyelocytic leukemia cells ${ }^{43}$. Whether JHDM1F 
activity influences the methylation status of $\mathrm{H} 3 \mathrm{~K} 9$ or normal $\mathrm{HSC}$ fate decisions remains to be explored. In contrast, removal of the active $\mathrm{H} 3 \mathrm{~K} 4 \mathrm{me} 3$ epigenetic mark, potentially by JARID1B, could repress transcription of "stemness" genes and favor lineage commitment (Fig. 7, lower panel). Other JmjC candidates (e.g. Hiflan) may also be involved in this process, underscoring the importance of further characterization of these enzymes in the context of HSC regulation. 


\section{ACKNOWLEDGEMENTS}

Authors acknowledge Mélanie Fréchette and Andrea Evelyn Mejia Alfaro for their assistance with animal care and transplantation experiments; IRIC's technological platform members: Danièle Gagné from Flow Cytometry Core Facility for help with cell sorting; Christian Charbonneau from Bio-imaging Core Facility for assistance with image acquisition and figure preparation; Raphaëlle Lambert, Pierre Chagnon and Simon Drouin from Genomic Core Facility for Q-RT-PCR and ChIP-chip experiments. This work was supported by grants from the Canadian Institute for Health Research (CIHR), the Canadian Cancer Society Research Institute and Fonds de Recherche en Santé du Québec (FRSQ) to GS. GS holds a Canada Research Chair in the Molecular Genetics of Stem Cells. SC is recipient of a CIHR Clinician-Scientist Fellowship Award and a Cole Foundation Transition Award. KH is recipient of a CIHR Post-Doctoral fellowship Award and a Cole Foundation Award. S.B.T. is recipient of National Health and Medical Research Council of Australia (NHMRC), Royal Australian College of Physicians and CIHR Postdoctoral Fellowships.

\section{AUTHORSHIP CONTRIBUTIONS}

S.C. and G.S. established the gene candidate list. M.S., J.C and S.C. contributed to isolation and functional assessment of highly purified HSC populations used for expression profile studies of gene candidates. S.C., K.J.H. and G.S. planned and performed the initial screen. S.C., K.J.H. and N.M. designed and performed validation experiments. S.C., N.M., K.J.H., S.B.T., J.C., E.D. J.K. and M.S. contributed to HSC isolation experiments required for initial screen, validation experiments and subsequent experiments. S.C. and N.M. performed confirmation experiments for shJaridlb-transduced cells including cell culture, progenitor assays and FACS. T.M. and S.C. performed RNA extraction and Q-RT-PCR analyses involving shJaridlb transduced cells. S.C., N.M. and J.C. performed LDA experiments and 
analyses of long-term recipient mice. B.T.W performed RNAseq studies. A.T. optimized and performed Q-RT-PCR assays for HoxA gene expression studies. E.D. performed Southern Blot analyses. J.R.L., T.M., S.C. and K.J.H. performed ChIP-chip experiments. M.S. and N.M. performed experiments involving co-transduction of NA1Ohd and shRNA constructs. S.C., G.S., J.K. and A.T. wrote the paper.

\section{CONFLICT OF INTEREST}

The authors declare no competing financial interests. 


\section{REFERENCES}

1. Fatemi M, Pao MM, Jeong S, et al. Footprinting of mammalian promoters: use of a CpG DNA methyltransferase revealing nucleosome positions at a single molecule level. Nucleic Acids Res. 2005;33(20):e176.

2. $\mathrm{He} \mathrm{YF}, \mathrm{Li} \mathrm{BZ}, \mathrm{Li} \mathrm{Z}$, et al. Tet-mediated formation of 5-carboxylcytosine and its excision by TDG in mammalian DNA. Science. 2011;333(6047):1303-1307.

3. Ito $\mathrm{S}$, Shen $\mathrm{L}$, Dai $\mathrm{Q}$, et al. Tet proteins can convert 5-methylcytosine to 5formylcytosine and 5-carboxylcytosine. Science. 2011;333(6047):1300-1303.

4. Kouzarides T. Chromatin modifications and their function. Cell. 2007;128(4):693705 .

5. Mills AA. Throwing the cancer switch: reciprocal roles of polycomb and trithorax proteins. Nat Rev Cancer. 2010;10(10):669-682.

6. Barski A, Cuddapah S, Cui K, et al. High-resolution profiling of histone methylations in the human genome. Cell. 2007;129(4):823-837.

7. De Santa F, Totaro MG, Prosperini E, Notarbartolo S, Testa G, Natoli G. The histone H3 lysine-27 demethylase Jmjd3 links inflammation to inhibition of polycomb-mediated gene silencing. Cell. 2007;130(6):1083-1094.

8. Issaeva I, Zonis Y, Rozovskaia T, et al. Knockdown of ALR (MLL2) reveals ALR target genes and leads to alterations in cell adhesion and growth. Mol Cell Biol. 2007;27(5):1889-1903.

9. Lee MG, Villa R, Trojer P, et al. Demethylation of H3K27 regulates polycomb recruitment and H2A ubiquitination. Science. 2007;318(5849):447-450.

10. Cloos PA, Christensen J, Agger K, Helin K. Erasing the methyl mark: histone demethylases at the center of cellular differentiation and disease. Genes Dev. 2008;22(9):1115-1140.

11. Di Lorenzo A, Bedford MT. Histone arginine methylation. FEBS Lett. 2011;585(13):2024-2031.

12. Secombe J, Eisenman RN. The function and regulation of the JARID1 family of histone H3 lysine 4 demethylases: the Myc connection. Cell Cycle. 2007;6(11):1324-1328.

13. Chang B, Chen Y, Zhao Y, Bruick RK. JMJD6 is a histone arginine demethylase. Science. 2007;318(5849):444-447.

14. Falnes PO, Johansen RF, Seeberg E. AlkB-mediated oxidative demethylation reverses DNA damage in Escherichia coli. Nature. 2002;419(6903):178-182.

15. Trewick SC, Henshaw TF, Hausinger RP, Lindahl T, Sedgwick B. Oxidative demethylation by Escherichia coli AlkB directly reverts DNA base damage. Nature. 2002;419(6903):174-178. 
16. Loh YH, Zhang W, Chen X, George J, Ng HH. Jmjd1a and Jmjd2c histone H3 Lys 9 demethylases regulate self-renewal in embryonic stem cells. Genes Dev. 2007;21(20):25452557.

17. Hayami S, Yoshimatsu M, Veerakumarasivam A, et al. Overexpression of the JmjC histone demethylase KDM5B in human carcinogenesis: involvement in the proliferation of cancer cells through the E2F/RB pathway. Mol Cancer. 2010;9:59.

18. Jepsen K, Solum D, Zhou T, et al. SMRT-mediated repression of an H3K27 demethylase in progression from neural stem cell to neuron. Nature. 2007;450(7168):415419.

19. Pospisil V, Vargova K, Kokavec J, et al. Epigenetic silencing of the oncogenic miR17-92 cluster during PU.1-directed macrophage differentiation. EMBO J. 2011;30(21):44504464.

20. Schmitz SU, Albert M, Malatesta $M$, et al. Jarid1b targets genes regulating development and is involved in neural differentiation. EMBO J. 2011;30(22):4586-4600.

21. Agger K, Cloos PA, Rudkjaer L, et al. The H3K27me3 demethylase JMJD3 contributes to the activation of the INK4A-ARF locus in response to oncogene- and stressinduced senescence. Genes Dev. 2009;23(10):1171-1176.

22. He J, Nguyen AT, Zhang Y. KDM2b/JHDM1b, an H3K36me2-specific demethylase, is required for initiation and maintenance of acute myeloid leukemia. Blood. 2011;117(14):3869-3880.

23. Northcott PA, Nakahara Y, Wu X, et al. Multiple recurrent genetic events converge on control of histone lysine methylation in medulloblastoma. Nat Genet. 2009;41(4):465-472.

24. Xiang Y, Zhu Z, Han G, et al. JARID1B is a histone H3 lysine 4 demethylase upregulated in prostate cancer. Proc Natl Acad Sci U S A. 2007;104(49):19226-19231.

25. Hope KJ, Cellot S, Ting SB, et al. An RNAi screen identifies Msi2 and Prox1 as having opposite roles in the regulation of hematopoietic stem cell activity. Cell Stem Cell. 2010;7(1):101-113.

26. Deneault E, Cellot S, Faubert A, et al. A functional screen to identify novel effectors of hematopoietic stem cell activity. Cell. 2009;137(2):369-379.

27. Simon C, Chagraoui J, Krosl J, et al. A key role for EZH2 and associated genes in mouse and human adult T-cell acute leukemia. Genes Dev. 2012;26(7):651-656.

28. Szilvassy SJ, Humphries RK, Lansdorp PM, Eaves AC, Eaves CJ. Quantitative assay for totipotent reconstituting hematopoietic stem cells by a competitive repopulation strategy. Proc Natl Acad Sci U S A. 1990;87(22):8736-8740.

29. Katsumoto T, Aikawa Y, Iwama A, et al. MOZ is essential for maintenance of hematopoietic stem cells. Genes Dev. 2006;20(10):1321-1330. 
30. Thomas T, Corcoran LM, Gugasyan R, et al. Monocytic leukemia zinc finger protein is essential for the development of long-term reconstituting hematopoietic stem cells. Genes Dev. 2006;20(9):1175-1186.

31. Ohta H, Sekulovic S, Bakovic S, et al. Near-maximal expansions of hematopoietic stem cells in culture using NUP98-HOX fusions. Exp Hematol. 2007;35(5):817-830.

32. Sekulovic S, Gasparetto M, Lecault V, et al. Ontogeny stage-independent and highlevel clonal expansion in vitro of mouse hematopoietic stem cells stimulated by an engineered NUP98-HOX fusion transcription factor. Blood. 2011;118(16):4366-4376.

33. Cellot S, Krosl J, Chagraoui J, Meloche S, Humphries RK, Sauvageau G. Sustained in vitro trigger of self-renewal divisions in Hoxb4hiPbx1(10) hematopoietic stem cells. Exp Hematol. 2007;35(5):802-816.

34. Yamane K, Tateishi K, Klose RJ, et al. PLU-1 is an H3K4 demethylase involved in transcriptional repression and breast cancer cell proliferation. Mol Cell. 2007;25(6):801-812.

35. Rinn JL, Kertesz M, Wang JK, et al. Functional demarcation of active and silent chromatin domains in human HOX loci by noncoding RNAs. Cell. 2007;129(7):1311-1323.

36. Dorrance AM, Liu S, Yuan W, et al. Mll partial tandem duplication induces aberrant Hox expression in vivo via specific epigenetic alterations. J Clin Invest. 2006;116(10):27072716.

37. Wang GG, Song J, Wang Z, et al. Haematopoietic malignancies caused by dysregulation of a chromatin-binding PHD finger. Nature. 2009;459(7248):847-851.

38. Sprussel A, Schulte JH, Weber S, et al. Lysine-specific demethylase 1 restricts hematopoietic progenitor proliferation and is essential for terminal differentiation. Leukemia. 2012;26(9):2039-2051.

39. Karrman K, Sallerfors B, Lenhoff S, Fioretos T, Johansson B. Cytogenetic evolution patterns in CML post-SCT. Bone Marrow Transplant. 2007;39(3):165-171.

40. Shah NK, Wagner J, Santos G, Griffin CA. Karyotype at relapse following allogeneic bone marrow transplantation for chronic myelogenous leukemia. Cancer Genet Cytogenet. 1992;61(2):183-192.

41. Catchpole S, Spencer-Dene B, Hall D, et al. PLU-1/JARID1B/KDM5B is required for embryonic survival and contributes to cell proliferation in the mammary gland and in ER+ breast cancer cells. Int J Oncol. 2011;38(5):1267-1277.

42. Allis CD, Berger SL, Cote $\mathbf{J}$, et al. New nomenclature for chromatin-modifying enzymes. Cell. 2007;131(4):633-636.

43. Arteaga MF, Mikesch JH, Qiu J, et al. The Histone Demethylase PHF8 Governs Retinoic Acid Response in Acute Promyelocytic Leukemia. Cancer Cell. 2013;23(3):376-89. 


\section{FIGURE LEGENDS}

Figure 1. JmjC gene expression in $\mathrm{HSC}$ /progenitor cell populations and selection for RNAi screen. A) Transcript levels of histone demethylases (HDM) in HSC enriched cell populations. Results show $\Delta \mathrm{CT}$ values determined by quantitative (Q) RT-PCR assays (with respect to endogenous Hprt expression levels, Ct 22) and represent average \pm SEM of 5 independently sorted HSC populations (bone marrow, n=3; E14.5 d.p.c. fetal liver, $n=2$ ). Frequencies of long term-repopulating HSCs in these populations are shown in Table S1. B) Comparison of HDM transcript levels detected in HSCs and total bone marrow cell populations. Relative transcript quantities (RQ) are shown in $\log 2$ scale, and represent the $\Delta \mathrm{CT}$ (HSC)/ $\Delta \mathrm{CT}$ (bone marrow) ratio determined by quantitative RT-PCR assays (average \pm SEM, $\mathrm{n}=3)$. An HSC expression score was implemented based on expression levels $(\Delta \mathrm{CT})$ and differential expression (RQ) of individual HDM, to rank gene candidates according to relative expression in HSC vs mature cells: gene not expressed in HSC, -2; less $(<)$ expressed in HSC vs mature cells, -1 ; more (>) expressed in HSC, +1; equally expressed, 0. C) List of the $23 \mathrm{HDM}$ candidates tested in primary screen. HDMs sub-families sharing similarities outside the catalytic domain are denoted by different shading. Left column, the revised current terminology; central column, synonyms; right column, proposed substrate specificity $^{10,42}$. Four HDM genes were excluded from the screen: Jaridld and Uty map to chromosome $\mathrm{Y}$ and are thus likely not required for regulation of HSC activity; Pla3g4b belongs to the cytosolic phospholipase A2 family; Jhdmle knockdown could not be achieved by any hairpin in two independent experiments. D) Schema of shRNA retroviral vector backbone (top), and experimental outline (bottom) of the primary screen at the bottom. At 16 week after transplantation, increase in the proportion of $\mathrm{GFP}^{+}$peripheral blood leukocytes above their input levels reflects knockdown of a negative regulator of HSC activity (green box), and the inverse outcome denotes a positive HSC regulator (red box). 
Figure 2. HDM hit identification. A) The selection threshold score for genes was calculated from the expression score (Fig. 1B) and HSC activity score or biological score, (Fig. 2B). Biological score represents the number of shRNAs per HDM which modulate HSC activity in recipients above or below the $95 \%$ confidence interval range established for control shLuc cells (dotted blue lines in Fig. 2B). Selection threshold score of 2 and above identifies hits selected for validation experiments. B) Contributions of $\mathrm{GFP}^{+}$(shRNAtransduced) cells to peripheral blood reconstitution of recipients at 20 weeks after transplantation. Results are presented as proportions $\mathrm{GFP}^{+}$cells within the transplant-derived $\left(\mathrm{CD} 45.1^{+}\right)$peripheral blood cells and are normalized for the gene transfer efficiency determined on the day of transplantation (day 0). Green shaded areas, suppressors of HSC activity; red shaded areas, enhancers of HSC activity. Raw data for gene transfer rates and blood reconstitution levels for all recipients are provided in Table S4.

Figure 3. Validation assays for identified hits. A) Schema of experimental design. B)

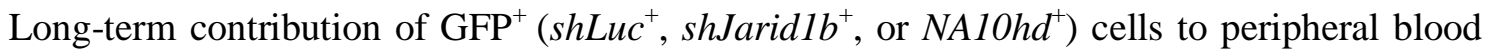
reconstitution of recipients; gene transfer $>80 \%$ for all conditions. Left panel: recipients of day 0 cells; central and right panel, recipients of day 7 cells. NA10hd, cells engineered to overexpress NUP98Hoxa10-homeodomain fusion protein and green fluorescent protein (GFP). C) Evaluation of Jaridlb knockdown in $\mathrm{GFP}^{+}$shJaridlb-transduced cells compared to shLuc controls. Results represent average \pm SEM $(\mathrm{n}=4)$ RQ values determined for 6 different hairpins. Bars with dashed lines correspond to shRNA constructs (sh5,6 and 1) that did not achieve significant (ie >30\%) knockdown of Jaridlb in BM HSC. D) Long-term contribution of $\mathrm{GFP}^{+}\left(s h L u c^{+}\right.$, or $s h \mathrm{Moz}^{+}$, or $\left.s h J h d m l f^{+}\right)$cells to peripheral blood reconstitution in recipients of day 0 cells. Each recipient received a $1 / 4$ of the transduced cell population, or twice the number of input cells transplanted for validation experiment shown 
in Fig. 3A. E). Short-term (3 weeks) contribution of $\mathrm{GFP}^{+}\left(s h L u c^{+}\right.$or $s h J h d m l f^{+}$-transduced) cells to peripheral blood reconstitution in recipients of day 0 cells. GT=99\% for all conditions. Experiment (as in Fig. 4D) was repeated to include all hairpins against Jhdmlf. F) Evaluation of Jhmdmlf knockdown in $\mathrm{GFP}^{+}$shJhdmlf-transduced cells compared to shLuc controls. Results represent average $\pm \operatorname{SEM}(n=3)$. RQ values determined for 5 different hairpins. G) Summary of screen results.

Figure 4. Jarid $1 b$ knockdown decreases hematopoietic cell differentiation in vitro. A) Left panel: Jaridlb knockdown increases yields of mononuclear cells in cultures initiated with shJarid-transduced $\mathrm{HSC}$ /progenitor cell populations (mean $\pm \mathrm{SD}, \mathrm{n}=2$ ). Right panel: Wright-stained cytospin preparations of cells on day 9 of culture, 40x magnification, white arrows indicate primitive cells. B) shJaridlb suppresses in vitro differentiation of HSC/progenitor cell populations. Proportions of $\mathrm{Gr}^{+}$cells on day 9 of culture were determined by flow cytometry. Each dot represents an independent culture. C) Jaridlb knockdown enhances in vitro expansion of myeloid colony forming cells (CFC). The increase in CFC numbers was calculated from MNC and CFC numbers determined on days 2 and 9 (mean $\pm \mathrm{SD}, \mathrm{n}=4$ ). D) Images of the predominant colony types. shJaridlb, colony forming unit granulocyte-macrophage (CFU-GM), high proliferative potential; shMoz, colony forming unit macrophage (CFU-M), low proliferation. Left panels, bright field; right panels, epifluorescence. E) Proportions of the highly proliferative CFU-GM in cultures of shRNAtransduced cells (mean $\pm \mathrm{SD}, \mathrm{n}=4$ ). F) Q-RT-PCR-based comparison of cell fate-associated transcript levels in day 7 (Fig. 3A) shJaridlb and shMoz-cells compared to shLuc controls.

Figure 5. In vitro-expanded shJarid1b-HSC retain long-term in vivo multipotency. A) Analysis of hematopoietic tissues in recipients of day 7 cells (Fig. 3B) at 1 year after 
transplantation. From left to right: first panel, spleen weight; second panel, the total numbers of bone marrow cells pooled from pelvis, femur and tibia; third panel, CFC frequency in the $\mathrm{GFP}^{+}$bone marrow cell populations; fourth panel, proportions of $\mathrm{GFP}^{+}$multilineage progenitors (Colony Forming Unit-Granulocyte, Erythrocyte, Monocyte, Megakaryocyte, CFU-GEMM). Dots in first plot represent the numbers of individual mice for which all the described parameters were analyzed. B) Contribution of day 7 (Fig. 3A) shJarid $1 \mathrm{~b}\left(\mathrm{GFP}^{+}\right)$ cells to reconstitution of myeloid $\left(\mathrm{Mac1}^{+}\right)$, B-lymphoid $\left(\mathrm{B} 220^{+}\right)$and T-lymphoid lineage $\left(\mathrm{CD}^{+}, \mathrm{CD}^{+}\right)$at 1 year after transplantation. An example of typical reconstitution observed in all recipients $(\mathrm{n}>10)$ is shown. C) Jarid1b knockdown promotes the in vitro expansion of LTR-HSCs. Upper panel, experimental outline. Lower panel, CRU numbers in freshly sorted (i.e., input) and day 7 shRNA-transduced cell populations (mean \pm SE). shJaridlb CRUs were determined in 2 independent experiments (see Table S6). D) Clonal analysis of proviral integrations in DNA isolated from hematopoietic tissues of mouse from shJaridlb cohort introduced in Fig. 5C. DNA was digested with EcoRI which cuts once within the provirus such that each DNA fragment recognized by the ${ }^{32} \mathrm{P}$-labelled $G f p$ probe represents a unique integration event. Mouse ID\#, the total dose of transplanted cells, and the estimated number of transplanted CRU are shown on top. T, thymus; S, spleen; BM, bone marrow.

\section{Figure 6. Jarid1b knockdown modulates molecular mechanisms implicated in} maintenance of stemness. A) Quantification of Hox gene transcripts in shJaridlb-cells and shLuc controls as assessed by RNA sequencing (RNAseq) analysis. For each Hox cluster (a and b) genes, FPKM (fragments per kilobase per million reads) expression values are shown for both conditions. Error bars indicate SD. RNA was isolated from HSC enriched cells in culture (4 days following retroviral infection), and only cultures with gene transfer rates $>90 \%$ were selected. For each condition, two biological replicates were sequenced. B) 
Average FPKM and fold-change expression values of the 40 most upregulated (FPKM>1 for shJaridlb-cells) and C) downregulated (FPKM >1 for shLuc controls) genes from the RNAseq experiment described in Fig. 6A. Genes annotated to specific functions are specified by a cross mark in respective columns. Complete data for all differentially expressed genes (q-value < 0.05; all FPKM values included) shown in Table S7. D) Enrichment for H3K4me3 marks (black peaks) at the Hoxa7 and Hes1 loci in shJaridlb cells. Chromatin immunoprecipitation was carried out using day 7 (Fig. 5C) shJarid1b or shLuc-cells. Total H3K4me3 levels are presented in Fig. S6. E) Top panel: Experimental strategy for generation of Nup98Hoxa10-homeodomain (NA10hd) plus shRNA overexpressing cells. Following puromycin selection, the $\mathrm{Scal}^{+} \mathrm{CD}^{-} 3^{-} \mathrm{Gr}^{-} \mathrm{F} 4 / 80^{-}$NA10hd-transduced cells were infected with shLuc-, shMoz-, and shJaridlb 1b-carrying retroviruses. Lower panel: Jaridlb knockdown suppresses differentiation of NA10hd overexpressing cells. Proportions of $\mathrm{Gr}^{+} \mathrm{F} 4 / 80^{+}$(i.e. differentiated) cells in cultures were determined by flow cytometry on day 7 after shRNA transduction. Each dot represents individual culture comprising the transduced

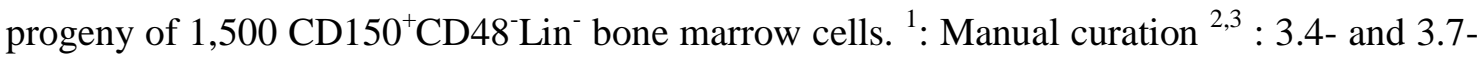
fold enrichment with false discovery rate of 4.6E-24 and 4.2E-11 in Gorilla bioinformatic tool. *Denotes high H3K4me3 densities, refer to Fig. 6D.

Figure 7. Proposed model for JARID1B activity in modulation of HSC fate. Grey shaded area: JARID1B erases the tri-methyl marks of $\mathrm{H} 3 \mathrm{~K} 4$ at stemness loci and represses activity of multipotency genes. Pink area: Decrease in JARID1B activity shifts balance in favour of histone methylases, preserving the active $\mathrm{H} 3 \mathrm{~K} 4 \mathrm{me} 3$ mark at stemness loci to sustain multipotency. 


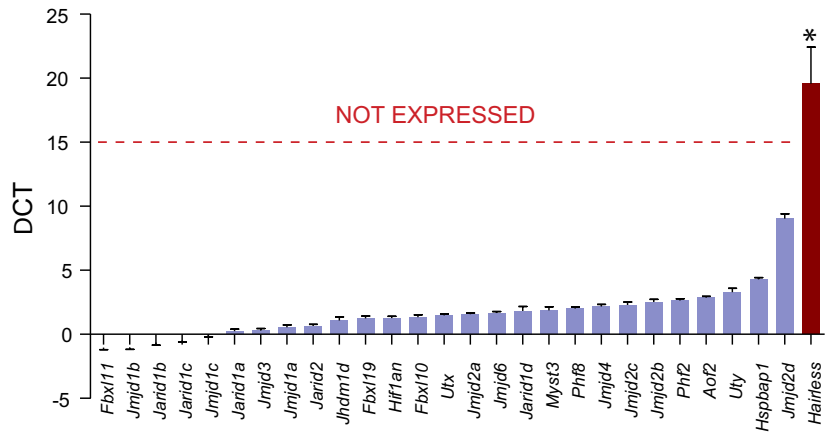

B

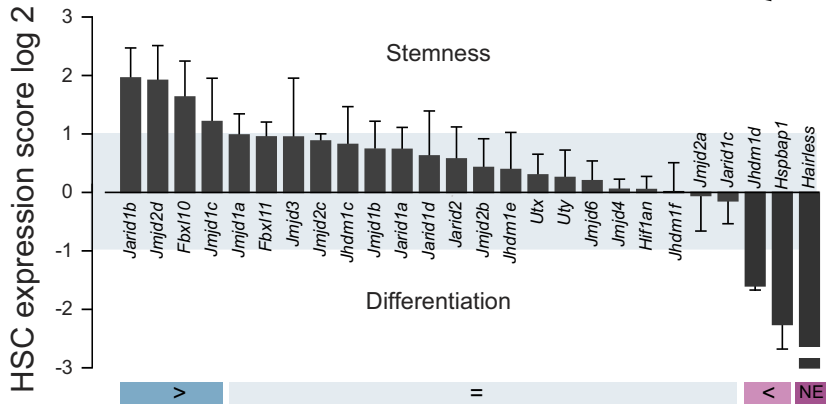

$\begin{array}{llllll}\text { HSC expression score } & 1 & 0 & -1 & -2\end{array}$

\begin{tabular}{|c|c|c|}
\hline NAME & SYNONYMS & SUBSTRATE \\
\hline $\begin{array}{l}\text { KDM2A } \\
\text { KDM2B }\end{array}$ & $\begin{array}{l}\text { JHDM1A / FBXL11 } \\
\text { JHDM1B / FBXL10 } \\
\text { JHDM1D / KIAA1718 } \\
\text { JHDM1F / PHF8 }\end{array}$ & 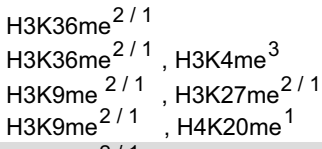 \\
\hline $\begin{array}{l}\text { KDM3A } \\
\text { KDM3B }\end{array}$ & $\begin{array}{l}\text { JMJD1A / JHDM2A / TSGA } \\
\text { JMJD1B } \\
\text { JMJD1C } \\
\text { HR }\end{array}$ & $\begin{array}{l}\mathrm{H} 3 \mathrm{~K} 9 \mathrm{me}^{2 / 1} \\
\mathrm{H} 3 \mathrm{~K} 9 \mathrm{me}^{2 / 1}\end{array}$ \\
\hline $\begin{array}{l}\text { KDM4A } \\
\text { KDM4B } \\
\text { KDM4C } \\
\text { KDM4D }\end{array}$ & $\begin{array}{l}\text { JMJD2A / JHDM3A } \\
\text { JMJD2B / JHDM3B } \\
\text { JMJD2C / JHDM3C / GASC1 } \\
\text { JMJD2D / JHDM3D }\end{array}$ & 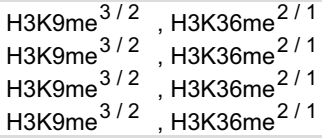 \\
\hline $\begin{array}{l}\text { KDM5A } \\
\text { KDM5B } \\
\text { KDM5C }\end{array}$ & $\begin{array}{l}\text { JARID1A } \\
\text { JARID1B } \\
\text { JARID1C } \\
\text { JARID2 }\end{array}$ & $\begin{array}{l}\mathrm{H} 3 \mathrm{~K} 4 m e^{3 / 2} \\
\mathrm{H} 3 \mathrm{~K} 4 \mathrm{me}^{3 / 2} \\
\mathrm{H} 3 \mathrm{~K} 4 \mathrm{me}^{3 / 2}\end{array}$ \\
\hline $\begin{array}{l}\text { KDM6A } \\
\text { KDM6B }\end{array}$ & $\begin{array}{l}\text { UTX } \\
\text { JMJD3 } \\
\text { JMJD4 } \\
\text { JMJD5 } \\
\text { JMJD6 / PTDSR / PSR } \\
\text { HSPBAP1 } \\
\text { HIF1AN }\end{array}$ & $\begin{array}{l}\mathrm{H} \mathrm{R} 2 \mathrm{me}^{2}, \mathrm{H}^{2} \mathrm{R} 3 \mathrm{me}^{2} \\
\text { HIF1a-N803 }\end{array}$ \\
\hline
\end{tabular}

HIF1AN HIF1a-N803

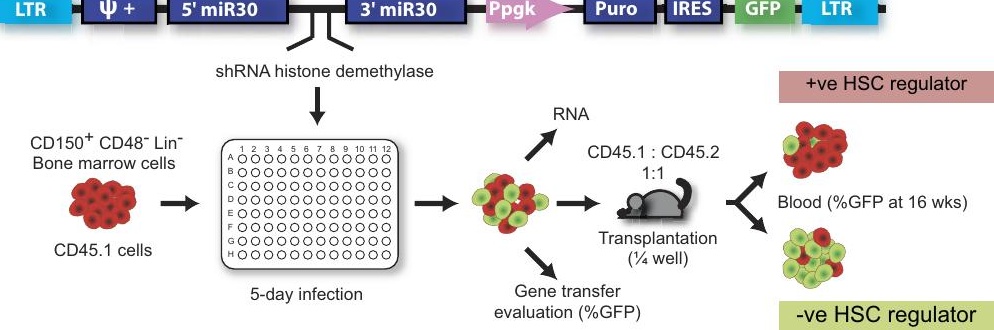


STS $=$ IF $(($ HSC activity score: Fig. $2 \mathrm{~B})+($ Expression score: Fig. 1B $)) \geq 2 \rightarrow$ HIT

B

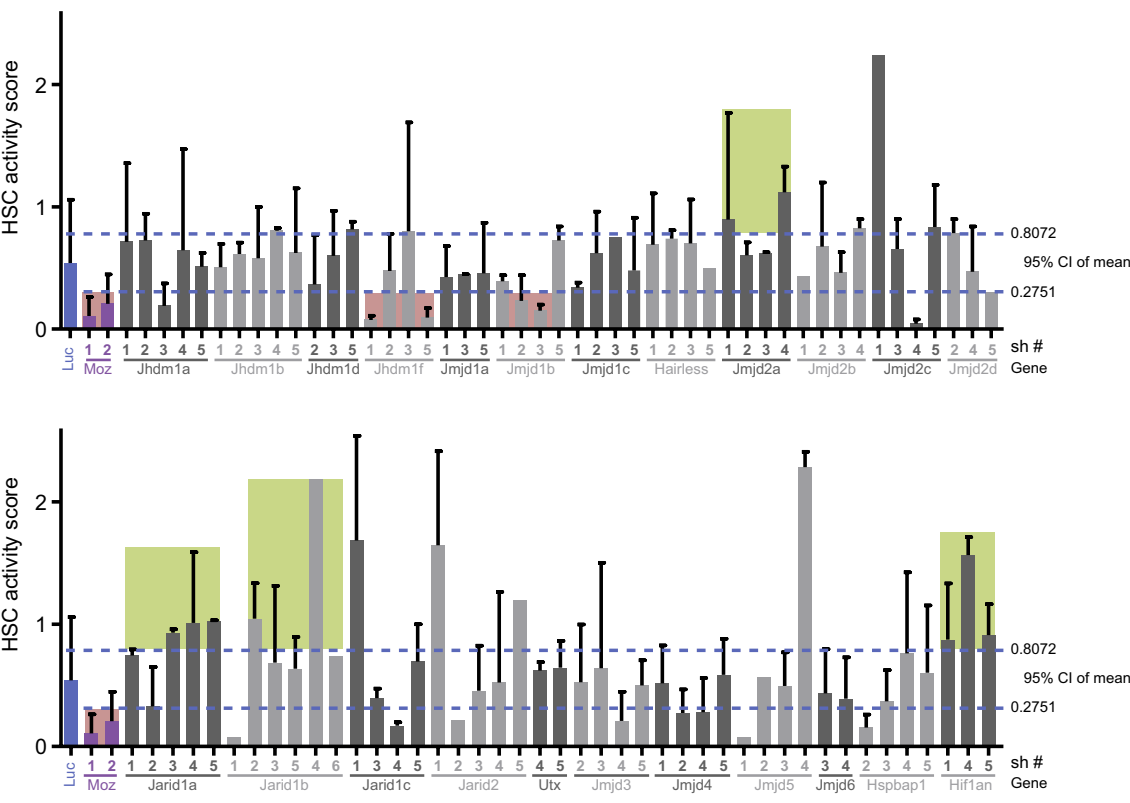

Cellot S. et al, Fig. 2 
A

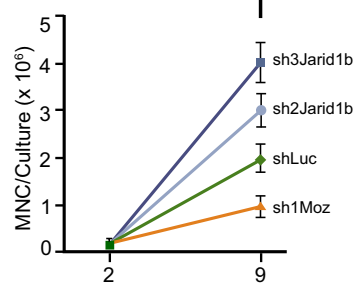

Time in Culture (days)

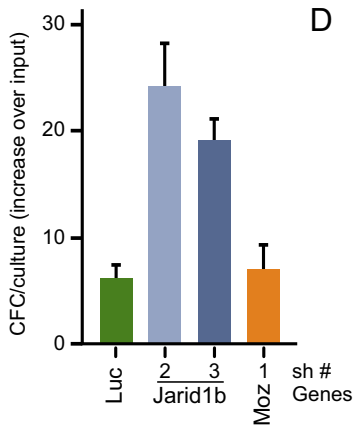

B

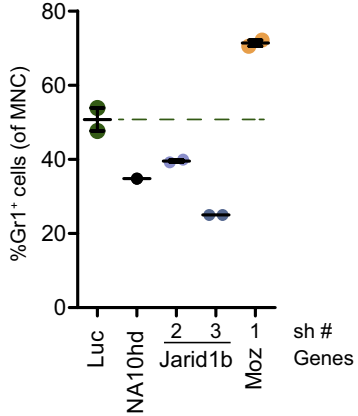

F

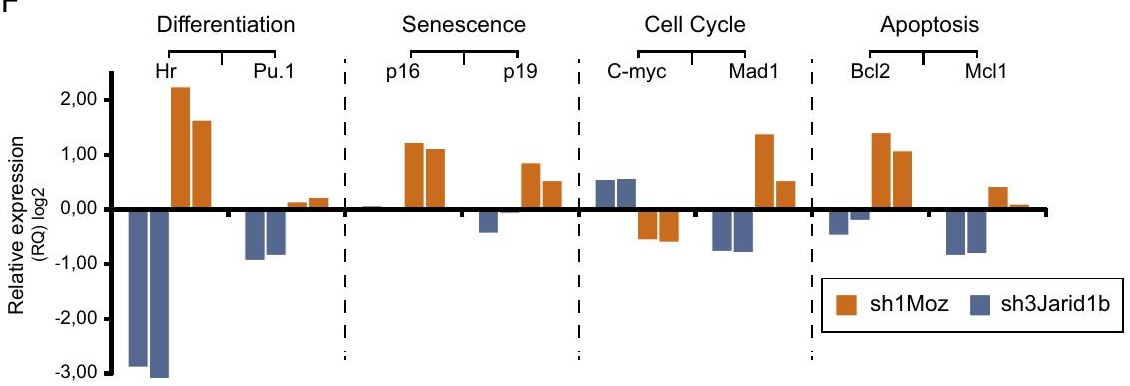

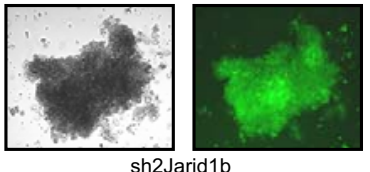

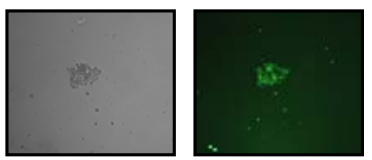

sh1Moz

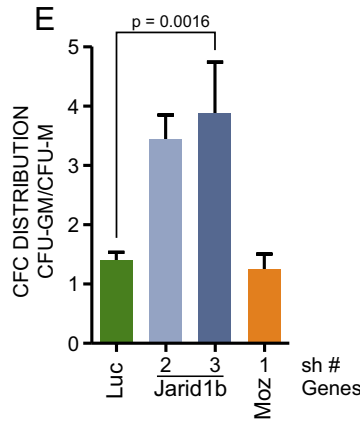



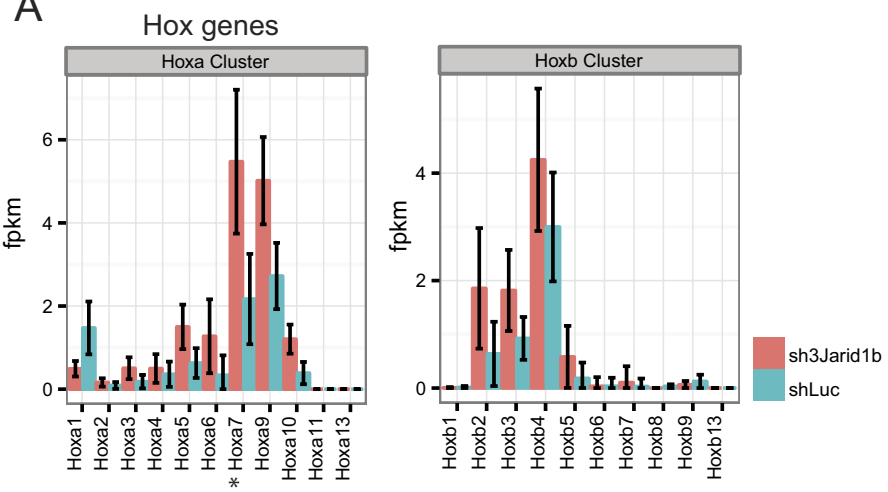

B

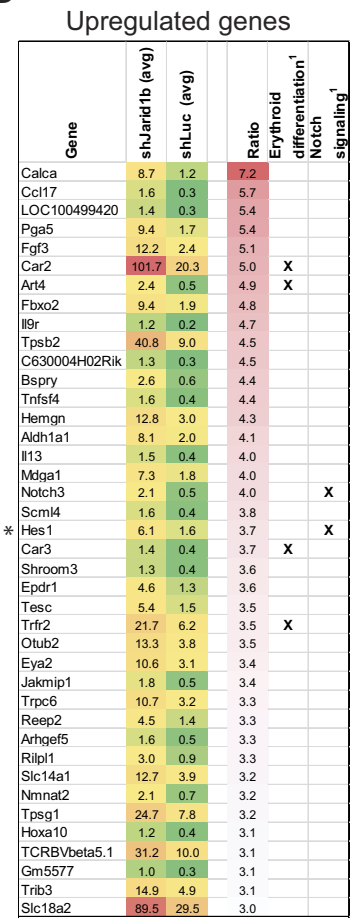

D

Hoxa7 i2, $145,000 \mid \quad \begin{gathered}52,150,000 \mid \\ \text { shJarid1b-2-raw }\end{gathered}=$

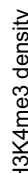

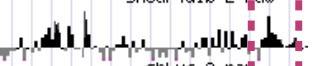
shLuc-e-rat

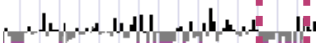
in Genes Based on Un ifrot, Refsec Hoxa?

- $=$

C

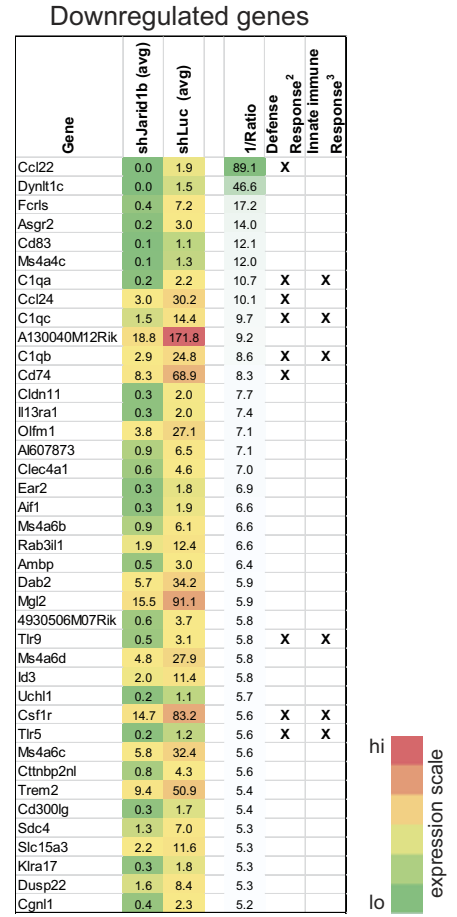

Hes1

385; 0 जol $10 \quad 10 \mathrm{kbF}$

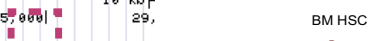

a sh3Jarid1b

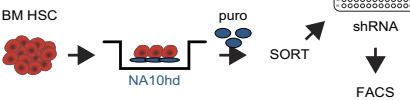
shLuc cins ucsc known

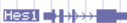

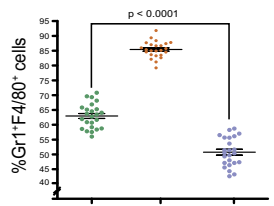

shLuc shMoz sh3Jarid1b 


\section{MULTIPOTENCY}

$?$

$\mathrm{H} 3-\overline{\mathrm{K}}_{9} \mathrm{R}$ A T Y $\mathrm{K}_{4} \mathrm{~T} \mathrm{R}_{2} \mathrm{~A}$

JARID1B

"stemness" genes

(Hoxa, others?)

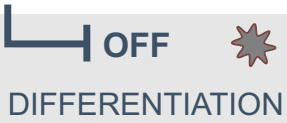

Cellot S. et al, Fig. 7 